УДК 327

Белла НОЧВИНА

Олег РВАЧЕВ

\title{
РОЛЬ РОССИЙСКОЙ ФЕДЕРАЦИИ НА ЕВРОПЕЙСКОМ ГАЗОВОМ РЫНКЕ
}

\begin{abstract}
Аннотация. В статье анализируется современное состояние общеевропейского газового рынка, определяется роль Российской Федерации на нём. Авторы оценивают эффективность газовой политики Европейского союза. Выявлен круг проблем, оказывающих негативное влияние на стабильность энергетической безопасности ЕС. Изучаются методы, используемые европейским интеграционным объединением для укрепления стабильности на газовом рынке ЕС, а также их влияние на российско-европейский газовый диалог. Подчёркивается растущая независимость энергетической политики Евросоюза, ранее находившейся под влиянием США. В заключении, сравнивая разные аспекты российских энергетических поставок с поставками других европейских энергоэкспортёров, авторы делают вывод о том, что РФ остаётся ключевым игроком на газовом рынке ЕС.
\end{abstract}

Ключевые слова: Евросоюз, Российская Федерачия, энергетическая безопасность; энергетический диалог; газовая дипломатия; энергоресурсы; энергозависимость.

\section{Нормативно-правовая база политики диверсификации Европейского союза}

Обеспечение энергетический безопасности является одним из приоритетов для правительств многих государств. Актуализация данного вопроса связана с рядом энергетических кризисов второй половины XX - начала XXI вв. и неутешительными прогнозами о мировых запасах невозобновляемых ресурсов ${ }^{1}$. Уязвимыми к энергетическими кризисам на сырьевом рынке становятся государства-импортёры, которые не обладают углеводородами на собственной территории и зависят от внешних поставок. Страны - члены ЕС являются в этом отношении ярким примером, поэтому и Брюссель, и национальные правительства уделяют особое внимание вопросам энергобезопасности.

Система европейской энергетической безопасности выкристаллизовывается с середины XX в. В 1957 г. основано Европейское сообщество по атомной энергии с целью формирования общей энергетической политики, повышения стабильности и координации в энергетике. Следующая веха - встреча «Группы шести» в г. Рамбуйе 1975 г., где разработано понятие «энергетическая безопасность» и выработаны три её направления: поиск альтернативы углеродным ресурсам Ближнего Востока; развитие альтернативных источников энергии; обеспе-чение свободного доступа стран-импортёров к углеводородному сырью. В июне 1990

(C) Ночвина Белла Анатольевна - кандидат исторических наук, доцент кафедры истории, регионоведения и журналистики Нижегородского государственного лингвистического университета им. Н.А. Добролюбова. Adpec: 603155, Россия, Нижний Новгород, ул. Минина, д. 31а. E-mail: bella.nochtvina@mail.ru. Рвачев Олег Валентинович - студент Нижегородского государственного лингвистического университета им. Н.А. Добролюбова. Адрес: 603155, Россия, Нижний Новгород, ул. Минина, д. 31a. E-mail: rvachev-oleg@ mail.ru.

DOI: http://dx.doi.org/10.15211/vestnikieran420196873

${ }^{1}$ Прогноз развития энергетики мира и России до 2040 года. Институт энергетических исследований Российской академии наук совместно с Аналитическим центром при Правительстве Российской Федерации URL: https://www.eriras.ru/files/forecast_2040.pdf (дата обращения: 16.07.2019). 
г. нидерландским премьер-министром Рюдом Лобберсом выдвинута инициатива по созданию Европейского энергетического сообщества. Правовую базу сообщества составляют Энергетическая хартия 1991 г., Договор энергетической хартии 1994 г. и протокол к ней${ }^{1}$.

Ряд «газовых войн» между Россией и Украиной в 2000-е гг. нанёс болезненный «энергетический» удар по многим странам Центральной и Восточной Европы. Кризисы дали понять, что европейская система энергетической безопасности имеет уязвимые места: энергозависимость от узкого круга поставщиков энергоресурсов, а также нестабильность внутриполитической ситуации стран-транзитёров. Согласно статистике Европейской Комиссии, доля поставок газа в Евросоюзе из 3 крупнейших стран-экспортёров (Россия, Норвегия, Алжир) в середине 2000-х гг. возросла на 7\% по сравнению с 1990-м г. и составила $55 \%$ от потребления газа странами - членами $\mathrm{EC}^{2}$. Политическая элита Европейского союза связывает зависи-мость с энергоресурсами российского происхождения.

Проблема энергозависимости освещена и в Стратегии Могерини. В данном документе сохраняется недружественная позиция по реализации новых газовых проектов России, а также явно выражено недовольство по поводу экспортной монополии Газпрома ${ }^{3}$. Основным направлением по укреплению системы энергобезопасности остаётся политика диверсификации поставок.

В соответствии с положениями Стратегии энергетической безопасности Евровсоюза от 2006 г., одной из задач является достижение $20 \%$ уровня возобновляемых источников энергии (ВИЭ) в топливном балансе к 2020 г. По статистике Европейской Комиссии первичное производст-во возобновляемых источников энергии в странах ЕС в 2016 г. составило 226,5 млн т неф-тяного эквивалента (toe). Количество таких источников в период между 2006 и 2017 гг. увеличилось на 64,0\% (в среднем на 5,1 \% в год) ${ }^{4}$. Таким образом, ВИЭ составили $13,2 \%$ от общего валового внутреннего потребления энергии стран ЕС в 2016 г. Этого недостаточно для того, чтобы Евросоюз отказался от внешних поставок энергоресурсов, учитывая постоянно растущие экономическими показатели ${ }^{5}$, увеличивающие энергопотребности.

\section{Практика стратегического обеспечения газовой безопасности в Европейском союзе}

В результате политики ЕС по диверсификации «газовое присутствие» на европейских рынках наращивал Катар. В период с 2002 по 2012 гг. поставки СПГ из этой страны увеличились с 0,3 млрд до 27,3 млрд м ${ }^{3}$ (в основном в Великобританию, Италию и Испанию). Но с 2012 г. Доха перенаправляет экспорт газа, предназначенный из Европы, на традиционные для неё газовые рынки Азии, что связано с изменением ценовой конъюнктуры в связи с растущим спросом на газ Индии, Китая, Японии и Северной Кореи. При сравнении цен на азиатском и европейском рынке в 2016 г. экономическая выгода очевидна: 400 долл. за 1 м $^{3}$ в Японии и 230-250 долл. за 1 м $^{3}$ в Великобритании. На наш взгляд, трудно утверждать, что Катар - надёжная страна-экспортёр энергоресурсов, готовая обеспечивать растущие

\footnotetext{
${ }_{1}^{1}$ Фененко А.В. Современная история международных отношений: 1991-2016. М., 2017. С. 197.

2 Imports of energy products - recent developments. European Commission EU. URL: https://ec.europa.eu/eurostat/ statistics-explained/index.php/EU_imports_of_energy_products_-_recent_developments (дата обращения: 26.11.2018).

3 Кавешников Н.Ю. Энергетическая безопасность в стратегии Могерини: выводы для России. Современная Европа, №1, 2017. С. 28.

4 Renewable energy statistics. European Comnission. URL: https://ec.europa.eu/eurostat/statistics-explained/index. php?title=Renewable_energy_statistics\#Renewable_energy_produced_in_the_EU_increased_by_two_thirds_in_20072017 (дата обращения: 14.06.2019).

${ }^{5}$ Borondino R. Flash estimate for the second quarter of 2018. Eurostat Press Office. URL: https://ec.europa.eu/eurostat/ documents/2995521/9105264/2-14082018-BP-EN.pdf/e28c60ea-1ad0-47fd-b7e1-668cdb9ba016 (дата обращения: 27.11.2018).
} 
потребности ЕС вопреки своим экономическим интересам. Более того, надёжность катарских поставок энергоресурсов в Евросоюз ставит под вопрос дипломатический кризис между Катаром и рядом других стран Аравийского полуострова и Северной Африки, разгоревшийся в 2017 г. Эскалация конфронтации с другими странами арабского мира может повлиять на безопасность поставок. Обеспокоенность ЕС вызывает и путь транспортировки газа, пролегающий через Аденский залив - место повышенной активности пиратов. За 2017 г. произошло более 10 нападений на суда различных государств.

В рамках проводимой политики диверсификации Европейский союз наращивает объём поставок СПГ из Соединённых Штатов. В своём совместном заявлении от 25 июля 2018 г. в Вашингтоне председатель Еврокомиссии Юнкер и президент Трамп согласились укрепить стратегическое сотрудничество в энергетике между ЕС и США. После этой встречи действительно наблюдается рост поставок американского СПГ на европейский рынок: если в 2017 г. в ЕС было поставлено 2,2 млрд м ${ }^{3}$ СПГ, то в 2018 г. - 3,3 млрд м ${ }^{3}{ }^{1}$ Однако российский газ всё равно остаётся более предпочтительным вариантом по ряду причин: вопервых, американские поставки СПГ экономически невыгодны для Евросоюза - сжиженный газ из США неконкурентоспособен в связи с высокой себестоимостью ${ }^{2}$. Во-вторых, возникает проблема недостаточной развитости инфраструктуры в США. Майкл Мур в интервью с «РИА Новости» подчеркнул, что зимой 2017 г. американские СПГ терминалы не справлялись с внутренним потреблением в связи с понижением температуры. В-третьих, российский СПГ имеет преимущество над американским и в ценовом измерении: «Новатэк» поставляет СПГ в Евро-пу по цене 3,15 долл. за мил. тепловых ед. топлива, а США - по 7-8 долл. ${ }^{3}$ Не случайно, Россия активно наращивает поставки СПГ в ЕС, закрепив за собой статус лидера по результатам февраля 2019 г. - общий объём поставок в данном месяце составил 1,41 млн т, оттеснив на второе место Катар. США поставили лишь 0,64 млн т.

Новым «газовым игроком» на европейской газовой арене стал Азербайджан. Летом 2018 г. открыт проект «Южный газовый коридор», который будет транспортировать азербайджанский газ в Турцию и ЕС по Южно-Кавказскому, Трансанатолийскому и Трансадриатическому газопроводам. Но сможет ли Азербайджан заполнить трубу на 16 млрд $\mathrm{M}^{3}$, учитывая тот факт, что Баку с 2017 г. возобновил покупку российского газа, так как возникли проблемы с ресурсной базой Южного газового коридора - Шах-Дениз? Ответа на этот вопрос нет. Да и объём поставок азербайджанского газа в Европу в соответствии с контрактом будет составлять всего 10 млрд м³, в то время как Газпром поставляет 192,2 млрд $\mathrm{M}^{3}$. Надёжность данного поставщика будет проверена в следующем десятилетии.

В итоге, политика диверсификации не помогла Европейскому союзу разрешить актуальную проблему - зависимость от российского газа. Альтернативные страныэкспортёры на данный момент не зарекомендовали себя как надёжные поставщики, в т.ч. по причине нестабильности внутриполитической и/ или региональной ситуации и высоким конфликтным потенциалом; увеличением внутреннего спроса на энергоресурсы, приводящим к сокращению поставок на внешние рынки.

Иначе обстоит ситуация с Россией, надёжным поставщиком, который за десятилетия энергетического диалога с Европой, несмотря на множество политических «барьеров»,

\footnotetext{
${ }^{1}$ EU-US. Lng Trade. European Comission URL: https://ec.europa.eu/energy/sites/ener/files/eu-us_lng_trade_folder.pdf (дата обращения: 10.06.1209).

Vielfalt macht unabhängig. Auswärtiges Amt 2018. URL: https://www.auswaertiges-amt.de/de/ aussenpolitik/themen/energie/fakten-zur-deutschen-energieversorgung/2142472 (дата обращения: 27.11.2018).

${ }^{3}$ Гарантия лучшей цены: Россия вытесняет США с европейского рынка СПГ. URL: https://ria.ru/20190306/15515 59537.html (дата обращения:10.06.2019).
}

Научно-аналитический вестник ИЕ РАН, 2019, №4 
продолжает «сверять часы» с Евросоюзом, постепенно адаптируясь к новым внешнеполитическим реалиям ${ }^{1}$. За время партнёрства в энергетической сфере создана необходимая инфраструктура и нормативно-правовая база. Национальные компании двух сторон имеют богатый опыт взаимодействия друг с другом, в т.ч. многочисленные энергетические проекты. Несмотря на политику диверсификации ЕС, поставки российского газа достигли рекордных отметок: 200,8 млрд м ${ }^{3}$ в 2018 г. $^{2}$, что подтверждает незаменимость российского газа и его экономическую выгоду для импортёров. За десятилетие российская сторона сделала значимый вклад в укрепление энергетической безопасности Европы, поддерживая инициативы по строительству новых газопроводов: «Северный поток», «Северный поток - 2» и «Турецкий поток», которые, как отмечает С.В. Лавров, «являются коммерческими, отвечают интересам европейских стран и вносят вклад в диверсификацию маршрутов поставок российского природного газа в Европу, снижая транзитные риски и укрепляя европейскую энергобезопасность»³.

Польша, Украина и прибалтийские страны при поддержке США политизируют коммерческую сферу, превращая вопрос постройки «Северного потока - 2» в камень преткновения в выработке общеевропейского энергетического вектора. Политическая элита каждой из этих стран утверждает, что проект используется Москвой в политических целях и лишь усиливает зависимость от российского газа. Так, министр иностранных дел Польши Яцек Чапутович предложил оказать давление на страны, которые поддерживают проект. Такая позиция обусловлена тем, что Польша и Украина потеряют дивиденды от транзита газа через свою территорию, так как основные газовые потоки будут направлены по новым газопроводам.

Для США сокращение поступления российского газа на рынок ЕС также экономически выгодно, поэтому они предпринимают резкие политические выпады в сторону странпартнёров энергетического проекта «Северный поток - 2», особенно ФРГ. Так, президент США Д. Трамп в ходе выступления 25 сентября 2018 г. на 73-й сессии ГА ООН заявил, что «Германия станет полностью зависимой от российской энергетики, если она немедленно не изменит курс. Здесь, в Западном полушарии, мы привержены сохранению нашей независимости от посягательств экспансионистских иностранных держав» ${ }^{4} .13$ января 2019 г. Посол США в Германии вопреки нормам, регулирующим действия загранучреждений, направил письма с санкционными угрозами немецким компаниям, участвующим в проекте. Накануне данного события министр иностранных дел ФРГ Хайко Маас в рамках новогоднего приёма Восточного комитета немецкой экономики 10 января 2019 г. в Берлине сформулировал официальную позицию ФРГ, заявив: «Я хочу ещё раз сказать об этом ясно, мы не хотим никаких изменений по российско-германскому проекту “Nord Stream - 2"»" 5 .

\footnotetext{
1 Энтин М.Л., Энтина Е.Г. К конструированию будущих отношений между Россией и ЕС. Современная Европа, №5, 2017. С. 22.

2 Статистика поставок. Официальный сайт ПАО Газпром. URL: http://www.gazpromexport.ru/statistics/ (дата обращения: 10.06.2019).

3 Лавров С.В. В Москве заинтересованы в крепком Евросоюзе. РСМД. URL: http://russiancouncil.ru/analytics-andcomments/comments/v-moskve-zainteresovany-v-krepkom-evrosoyuze/?sphrase_id=21915106 (дата обращения: 01.12.2018).

${ }^{4}$ Noack R. Trump accused Germany of becoming «totally dependent» on Russian energy at the U.N. The Germans just smirked. The Washington Post. URL:https://www.washingtonpost.com/world/2018/09/25/trump-accused-germanybecoming-totally-dependent-russian-energy-un-germans-just-smirked/?utm_term=.6873d75c415d (дата обращения: 01.12.2018).

${ }^{5}$ Rede von Außenminister Heiko Maas anlässlich des Neujahrsempfangs des Ost-Ausschusses - Osteuropavereins der Deutschen Wirtschaft am 10. Januar 2019 in Berlin. Auswärtiges Amt. URL: https://www.auswaertiges-amt.de/de/ newsroom/neujahrsempfang-ostausschuss/2176704 (дата обращения: 01.12.2018).
}

Научно-аналитический вестник ИЕ РАН, 2019, №4 


\section{Выводы}

На протяжении многих лет Российская Федерация остается ключевым партнёром ЕС в энергетическом диалоге. Несмотря на политические кризисы в двусторонних отношениях, Россия не выдвигала ультиматумы с целью политического давления на Европейский союз. Наоборот, Москва поддерживала экономические связи и в кризисные времена. Поставки трубного газа из России характеризуются не только экономической выгодой, но и стабильностью и непрерывностью. Что касается альтернативных газовых поставок из США, то на сего-дняшний день они не являются конкурентными российским поставкам ни по количественным показателям, ни по ценовым. Более того, Брюссель всё чаще выражает опасения по непредсказуемости и спонтанности внешнеполитических решений нынешней администрации США ${ }^{1}$. Надёжность поставок газа из Дохи и Баку также находится под сомнением по ряду политических и экономических причин.

Таким образом, газовый диалог между РФ и Евросоюзом укрепляет позитивную экономическую взаимозависимость - Россия не может рисковать поставками на свой крупнейший рынок сбыта углеводородов, в то время как ЕС не может потерять надёжный, качест-венный и одновре́менно дешёвый источник газа - которая, по нашему мнению, является основой взаимовыгодных межгосударственных отношений на европейском пространстве.

\section{Список литературы}

Белов В.Б. Перспективы реализации проекта «Северный поток - 2». Аналитическая записка №26 (122), $2018 . \quad$ URL: http://www.instituteofeurope.ru/images/uploads/analitika/2018/an12 2 2.pdf (дата обращения: 01.12.2018).

Кавешников Н.Ю. Энергетическая безопасность в стратегии Могерини: выводы для России. Современная Европа, №1, 2017.

Лавров С.В. В Москве заинтересованы в крепком Евросоюзе. Сайт РCMД. URL: http://rus siancouncil.ru/analytics-and-comments/comments/v-moskve-zainteresovany-v-krepkom-evrosoyuz e/?sphrase_id=21915106 (дата обращения: 01.12.2018).

Фененко А.В. Современная история международных отношений: 1991-2016. М., 2017.

Щербак И. Европейский союз в поисках модели урегулирования кризиса в Венесуэле. URL: http://instituteofeurope.ru/images/uploads/analitika/2019/an156.pdf (дата обращения: 14.05. 2019).

Энтин М.Л., Энтина Е.К. К конструированию будущих отношений между Россией и ЕС. Современная Европа, №5, 2017.

Borondino R. Flash estimate for the second quarter of 2018. Eurostat Press Office. URL: https:// ec.europa.eu/eurostat/documents/2995521/9105264/2-14082018-BP-EN.pdf/e28c60ea-1ad0-47fdb7e1-668cdb9ba016 (дата обращения: 27.11.2018).

\section{References}

Belov V.B. Perspektivy realizacii proekta «Severnyjpotok - 2». Analiticheskaya zapiska №26 (122), 2018. URL: http://www.instituteofeurope.ru/images/uploads/analitika/2018/an122.pdf (data

\footnotetext{
${ }^{1}$ Щербак И. Европейский союз в поисках модели урегулирования кризиса в Венесуэле. Аналитическая записка №5(156), 2019. URL: http://instituteofeurope.ru/images/uploads/analitika/2019/an156.pdf (дата обращения: 14.05.19). 
obrashcheniya: 01.12.2018).

Kaveshnikov N.Yu. Energeticheskaya bezopasnost' strategii Mogerini: vyvody dlya Rossii. Sovremennaya Evropa, №1, 2017. C. 28.

Lavrov S.V. V Moskve zainteresovany v krepkom Evrosoyuze. Sajt RSMD. URL: http://russian council.ru/analytics-and-comments/comments/v-moskve-zainteresovany-v-krepkom-evrosoyuze/?s phrase_id=21915106 (data obrashcheniya: 01.12.2018).

Fenenko A.V. Sovremennaya istoriya mezhdunarodnyh otnoshenij: 1991-2016. M., 2017.

Shcherbak I. Evropejskij soyuz v poiskah modeli uregulirovaniya krizisa v Venesuele. Analiticheskaya zapiska №5(156), 2019. URL: http://instituteofeurope.ru/images/uploads/analitika/ 2019/an156.pdf (data obrashcheniya: 14.05.2019).

Entin M.L., Entina E.K. K konstruirovaniyu budushchih otnoshenij mezhdu Rossiej i ES. Sovremennaya Evropa, №5, 2017.

Borondino R. Flash estimate for the second quarter of 2018. Eurostat Press Office. URL: https://ec.europa.eu/eurostat/documents/2995521/9105264/2-14082018-BP-EN.pdf/e28c60ea-1ad047fd-b7e1-668cdb9ba016 (data obrashcheniya: 27.11.2018).

\section{Role of the Russian Federation in the European Security of Energy Supply}

Authors. Bella Nochvina, Candidate of Sciences (History), Associate Professor of the Department of History, Regional Studies and Journalism, N.A. Dobrolyubov Linguistics University of Nizhny Novgorod. Address: 31a, ul. Minina, Nizhniy Novgorod, Russia, 603155. E-mail: bella.nochtvina@mail.ru. Oleg Rvachev, Student, N.A. Dobrolyubov Linguistics University of Nizhny Novgorod. Address: 31a, ul. Minina, Nizhniy Novgorod, Russia, 603155. E-mail: rvachevoleg@mail.ru.

Abstract. The paper analyzes the current situation in the European gas market and defines the role of the Russian Federation in it. A range of issues which has a detrimental impact on the EU gas security system is identified. The paper is devoted to studying methods conducted by the EU in order to strengthen stability of the EU gas market, their impact on the Russian-European energy dialogue is indicated. The authors evaluate the effectiveness of the EU energy policy. The growing independence of the energy policy of the European Union is underscored. In conclusion, comparing various aspects of the Russian energy supplies with supplies of other European energy exporters, it is concluded that the Russian Federation remains to be the crucial player on the European gas market.

Key words: European Union, Russian Federation, energy security; energy dialogue; gas diplomacy; energy resources; energy dependence.

DOI: http://dx.doi.org/10.15211/vestnikieran420196873 